\title{
Hypertonic solution-induced preconditioning reduces inflammation and mortality rate
}

\author{
Rosangela Nascimento Pimentel ${ }^{1}$, Ricardo Costa Petroni ${ }^{1}$, Hermes Vieira Barbeiro ${ }^{1}$, Denise Frediani Barbeiro ${ }^{1}$, \\ Mariana Macedo Andrade ${ }^{1}$, Suely Kumini Ariga ${ }^{1}$ and Francisco Garcia Soriano ${ }^{1,2^{*}}$ (i)
}

\begin{abstract}
Background: Dysregulated inflammatory response is common cause of organ damage in critical care patients. Preconditioning/tolerance is a strategy to prevent exacerbated inflammation. The aim of this study is to analyze hypertonic saline $7.5 \%$ as a potential inducer of preconditioning that protect from a lethal dose of LPS and modulates systemic inflammatory profile in mice.
\end{abstract}

Methods: Male Balb/C mice received intravenous (i.v.) injections of Hypertonic solution ( $\mathrm{NaCl} 7.5 \%)(0.8 \mathrm{ml})$ for 3 days, on day 8th was challenged with LPS $15 \mathrm{mg} / \mathrm{kg}$. Controls with Saline $0.9 \%$, urea and sorbitol were performed. Microarray of mRNA expression was analyzed from HS versus saline from macrophages to identified the pathways activated by HS.

Results: HS preconditioning reduced mortality after LPS injection as well reduced the cytokines release in plasma of the animals challenged by LPS. In order to check how HS induces a preconditioning state we measured plasma cytokines after each HS infusion. Repeated HS injections induced a state of preconditioning that reprograms the inflammatory response, resulting in reduced inflammatory cytokine production. A microarray of mRNA demonstrated that Hypertonic solution increased the expression of several genes in special Mapkbp1 and Atf3.

Conclusion: hypertonic solution induces preconditioning/tolerance reducing mortality and inflammatory response after LPS challenge.

Keywords: Sepsis, Inflammation, Preconditioning, Hypertonic solution, Tolerance

\section{Introduction}

Ischemia/reperfusion (IR), systemic inflammatory response (SIRS) and sepsis present dysregulated inflammatory response in different diseases, and are the main causes of hospitalization in the US and worldwide $[1,2]$. In addition to this, SIRS, IR and sepsis frequently affect surgical patients. These patients' common cause of death is shock which is non responsive to vascular contractile drugs. Preconditioning is used in some surgical situations in order to protect patients from vascular clamp and consequent ischemia [3-7]. Several studies have shown the therapeutic potential of hypertonic solutions

\footnotetext{
* Correspondence: gsoriano@usp.br

'Laboratório de Investigação Médica - LIM 51, Faculdade de Medicina,

Universidade de São Paulo (FMUSP), São Paulo, Brazil

${ }^{2}$ Emergências Clínicas do Departamento de Clínica Médica da Faculdade de Medicina da Universidade de São Paulo, Av Dr Arnaldo 455, room 3189, São Paulo, CEP 01246-903, Brazil
}

as treatment of different insults (sepsis, IR, SIRS). Studies with hypertonic sodium chloride solution revealed a prompt blood pressure restoration in experimental severe hemorrhagic shock [8-12]. Hypertonic solution treatment was effective in reducing mortality rate of endotoxemic rats [13], as well as prevented lung injury by LPS in the experimental model of ARDS [14, 15]. Hypertonic solution has been used in sepsis' experimental studies and in small clinical studies $[9,16,17]$. In these studies, hypertonic solution improved tissue perfusion and reduced inflammation. On the other hand, hyperosmolarity can be a side effect of hypertonic solution used for therapeutic purposes.

Recent studies showed that hyperosmolarity causes cell stress activating intracellular MAP kinases pathway [18-20]. As a consequence of osmotic stress there is an 
activation of a nonspecific inflammatory response with release of cytokines [20]. IL1 $\beta$ in human aortic endothelial cells, IL6 in peritoneal macrophages of rats and IL8 in human peripheral blood mononuclear cells [9, 17, 21]. Small stress with different substances (e.g. LPS or cytokines) repeated several times can induce a protection [22-24]. Taking in account the fact that osmotic stress induces an inflammatory response through MAPK pathway we hypothesized that small doses of hypertonic solution injected days before a LPS challenge could induce also a tolerance or preconditioning state in mice. The advantage of hypertonic solution is lower toxicity as inducer of tolerance in patients compared to LPS or cytokines. Thus, this strategy can be used in surgical patients at high risk to develop SIRS, ischemia/reperfusion or sepsis.

The aim of this study was to analyze hypertonic saline $7.5 \%$ as a potential inducer of preconditioning in mice, protecting animals from a lethal dose of LPS and modulating the systemic inflammatory profile when administrated previously to LPS.

\section{Material and methods \\ Mice}

Adult male Balb/c mice (8 weeks old, weighing 20-25 g) were used for experiments. The animals provided from the School Facility were specific pathogen-free (SPF). Animals were maintained in a climate-controlled facility with an automatic light/dark cycle, with food and water available ad libitum. All procedures were performed in accordance with the Guide for the Care and Use of Laboratory Animals published by the US National Institutes of Health. The study protocol was approved by the Research Ethics Committee of the São Paulo School of Medicine (\#0525/13).

Preconditioning test - doses of hypertonic saline ( $\mathrm{NaCl} 7.5 \%)$ Mice were divided into three groups. 1 - Group $2 \mathrm{ml} / \mathrm{kg}$ : animals received a dose of $2 \mathrm{ml} / \mathrm{kg}$ of $\mathrm{NaCl} 7.5 \%$ by intravenous tail injection at day one. The same dose was given at day three and day five. 2- Group $4 \mathrm{ml} / \mathrm{kg}$ : animals received a dose of $4 \mathrm{ml} / \mathrm{kg}$ of $\mathrm{NaCl} 7.5 \%$ by intravenous tail injection at day one. The same dose was given at day three and day five. 3- Group $8 \mathrm{ml} / \mathrm{kg}$ : animals received a dose of $4 \mathrm{ml} / \mathrm{kg}$ of $\mathrm{NaCl} 7.5 \%$ by intravenous tail injection at day one, a dose of $6 \mathrm{ml} / \mathrm{kg}$ of $\mathrm{NaCl} 7.5 \%$ by intravenous tail injection at day three and a dose of $8 \mathrm{ml} / \mathrm{kg}$ of $\mathrm{NaCl} 7.5 \%$ by intravenous tail injection at day five. At day 8 animals received an intraperitoneal injection of $10 \mathrm{mg} / \mathrm{kg}$ of LPS.

Preconditioning test - uses of different solutions at similar osmolarity of HS solution - $\mathbf{2 4 5 0}$ mOsm

In order to verify whether preconditioning effect of $\mathrm{HS}$ depends only of the solute $\mathrm{NaCl}$ or other solutes can induce a similar preconditioning state, we injected Urea and Sorbitol solutions at $45 \%$ concentration to match $7.5 \% \mathrm{NaCl}$ osmolarity. Mice were divided into three groups. 1- Group HS: animals received a dose of $4 \mathrm{ml} / \mathrm{kg}$ of $7.5 \% \mathrm{NaCl}$ by intravenous tail injection at day one, a dose of $6 \mathrm{ml} / \mathrm{kg}$ of $7.5 \% \mathrm{NaCl}$ by intravenous tail injection at day three and a dose of $8 \mathrm{ml} / \mathrm{kg}$ of $7.5 \% \mathrm{NaCl}$ by intravenous tail injection at day five. 2- Group HU animals received a dose of $4 \mathrm{ml} / \mathrm{kg}$ of $45 \%$ Urea by intravenous tail injection at day one, a dose of $6 \mathrm{ml} / \mathrm{kg}$ of $45 \%$ Urea by intravenous tail injection at day three and a dose of $8 \mathrm{ml} / \mathrm{kg}$ of $45 \%$ Urea by intravenous tail injection at day five. 3- Group $\mathrm{HB}$ animals received a dose of 4 $\mathrm{ml} / \mathrm{kg}$ of $45 \%$ Sorbitol by intravenous tail injection at day one, a dose of $6 \mathrm{ml} / \mathrm{kg}$ of $45 \%$ Sorbitol by intravenous tail injection at day three and a dose of $8 \mathrm{ml} / \mathrm{kg}$ of $45 \%$ Sorbitol by intravenous tail injection at day five. At day 8 animals received an intraperitoneal injection of $10 \mathrm{mg} / \mathrm{kg}$ of LPS.

Negative controls for hypertonic solution were checked. $\mathrm{NaCL}$ at 0.9 and $3.5 \% \mathrm{NaCl}, 20 \%$ Manitol were used at the same volume and injections time for check survival after LPS challenge.

\section{Survival rate}

After preconditioning, the animals were injected with lethal dose of LPS (15 mg/Kg; i.p.) monitored three times daily. We analyzed the survival rate for 15 days $(360 \mathrm{~h}$ ); after which, moribund mice were euthanized by $\mathrm{CO}_{2}$ inhalation.

\section{Plasma}

Blood samples were collected by means of cardiac puncture immediately before the mice were sacrificed. The samples were centrifuged at $1000 \mathrm{~g}\left(4^{\circ} \mathrm{C}\right)$ for $10 \mathrm{~min}$ and the supernatant (plasma) was placed in Eppendorf plastic tubes and stored at $-80^{\circ} \mathrm{C}$ for subsequent analysis.

\section{Cytokines}

The concentrations of interleukin IL- $\alpha$, IL-1 $\beta$, IL-2, IL4, IL6, IL10, IL12 p40, IL12 p70, IL-17A, IL-17F, IL-22, IL-23, IFN- $\gamma$, macrophage inflammatory protein (MIP) $-1 \alpha$, MIP-1 $\beta$ and tumor necrosis factor $\alpha$ (TNF- $\alpha$ ) in the plasma were determined by MilliPlex technology (\# MCYTOMAG-70 K, Merck KGaA, Darmstadt, Germany). The samples were analyzed on a MagPix system, and the data were collected by Luminex xPONENT software.

\section{Macrophages}

Peritoneal macrophages were collected from peritoneum cavity after saline or hypertonic infusion. Peritoneal cavity was washed with PBS buffer, the fluid collected was centrifuged and the pellet collected for RNA preparation. 


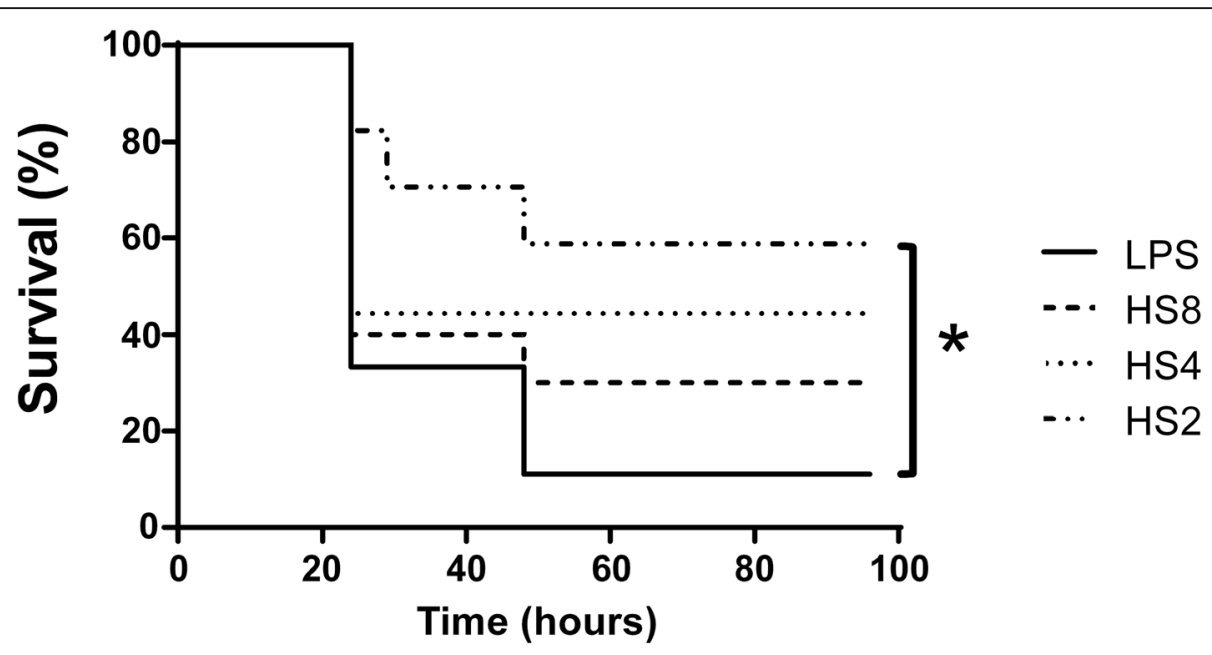

Fig. 1 Effect of the preconditioning with different doses and concentrations of $\mathrm{NaCl} 7,5 \%$ in endotoxemic animals. A- Animals were separated in 4 groups - LPS (received a lethal dose of LPS $15 \mathrm{mg} / \mathrm{kg}$ i.p); HS2 (received 3 doses in alternated days of $2 \mathrm{~mL} / \mathrm{kg}$ of $\mathrm{NaCl} 7.5 \%$ and a lethal dose of $15 \mathrm{mg} / \mathrm{kg}$ of LPS at the 8th day of the study); HS4 (received 3 doses of $4 \mathrm{~mL} / \mathrm{kg}$ of NaCl $7.5 \%$ and a lethal dose of $15 \mathrm{mg} / \mathrm{kg}$ of LPS at the 8 th day of the study); HS8 (received $4 \mathrm{~mL} / \mathrm{kg}$ at day one, $6 \mathrm{~mL}$ at day 3 and $8 \mathrm{~mL} / \mathrm{kg}$ at day 5 and a lethal dose of $15 \mathrm{mg} / \mathrm{kg}$ of LPS at the 8 th day of the study). ${ }^{*} p<0,05$ vs LPS; were used 20 animals for each group. B- Animals were separated in 5 groups - LPS (received a lethal dose of LPS 15 mg/kg i.p); HS7.5\% (received $4 \mathrm{~mL} / \mathrm{kg}$ at day one, $6 \mathrm{~mL}$ at day 3 and $8 \mathrm{~mL} / \mathrm{kg}$ at day 5 and a lethal dose of $15 \mathrm{mg} / \mathrm{kg}$ of LPS at the 8 th day of the study); HS3.5\% (received $4 \mathrm{~mL} / \mathrm{kg}$ at day one, $6 \mathrm{~mL}$ at day 3 and $8 \mathrm{~mL} / \mathrm{kg}$ at day 5 and a lethal dose of $15 \mathrm{mg} / \mathrm{kg}$ of LPS at the 8 th day of the study); NS0.9\% (received $4 \mathrm{~mL} / \mathrm{kg}$ at day one, $6 \mathrm{~mL}$ at day 3 and $8 \mathrm{~mL} / \mathrm{kg}$ at day 5 and a lethal dose of $15 \mathrm{mg} / \mathrm{kg}$ of LPS at the 8 th day of the study); and HM20\% received 20\% mannitol (received $4 \mathrm{~mL} / \mathrm{kg}$ at day one, $6 \mathrm{~mL}$ at day 3 and $8 \mathrm{~mL} / \mathrm{kg}$ at day 5 and a lethal dose of $15 \mathrm{mg} / \mathrm{kg}$ of LPS at the 8 th day of the study). ${ }^{*} p<0,05$ vs LPS; were used 20 animals for each group

\section{Preparation of RNA and microarray hybridization}

Total RNA was extracted from frozen peritoneal macrophage using TRIZOL Reagent (Life technologies, Carlsbad, CA, USA). The integrity and quality of the RNA was assessed using the Bioanalyzer (Agilent Technologies, Santa Clara, CA, USA). RNA integrity number
(RIN) values were $\geq 7.0$. Isolated RNA was further purified using an RNeasy Mini Kit (Qiagen, Hilden, Germany). Purified total RNA was amplified by in vitro transcription and converted to sense-strand cDNA using a WT Expression kit (Ambion/Applied Biosystems, Foster City, CA, USA). cDNA was fragmented and

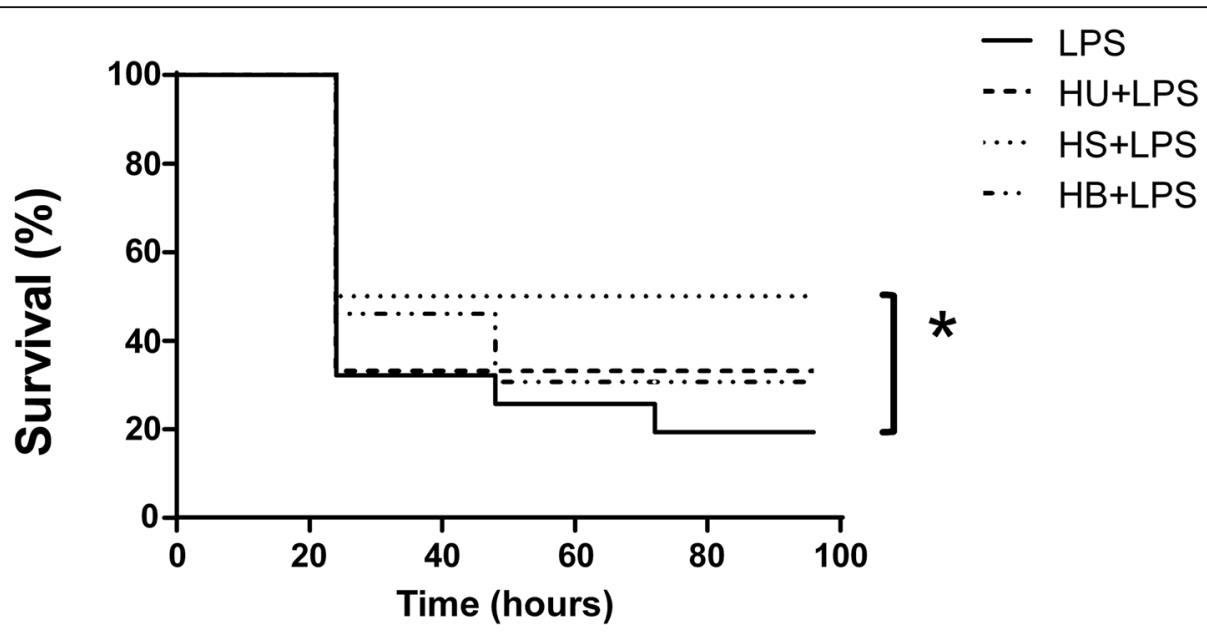

Fig. 2 Effect of preconditioning with different solution before LPS injection. Balb/c mice were divided into groups: LPS (received a lethal dose of $15 \mathrm{mg} / \mathrm{kg}$ of LPS); HS + LPS (received $4 \mathrm{~mL} / \mathrm{kg}$ on the first day, then $6 \mathrm{~mL} / \mathrm{kg}$ on the third day and $8 \mathrm{~mL} / \mathrm{kg}$ on the fifth day of Hypertonic Saline $7.5 \%$, then on the eighth day a lethal dose of $15 \mathrm{mg} / \mathrm{kg}$ of LPS); HU + LPS (received $4 \mathrm{~mL} / \mathrm{kg}$ on the first day, then $6 \mathrm{~mL} / \mathrm{kg}$ on the third day and $8 \mathrm{~mL} / \mathrm{kg}$ on the fifth day of Urea $45 \%$, then on the eighth day a lethal dose of $15 \mathrm{mg} / \mathrm{kg}$ of LPS); HB + LPS (received $4 \mathrm{~mL} / \mathrm{kg}$ on the first day, then $6 \mathrm{~mL} / \mathrm{kg}$ on the third day and $8 \mathrm{~mL} / \mathrm{kg}$ on the fifth day of Sorbitol $45 \%$, then on the eighth day a lethal dose of $15 \mathrm{mg} / \mathrm{kg}$ of LPS). ${ }^{*} p<0,05 \mathrm{vs}$ LPS group; were used 20 animals for each group 
A

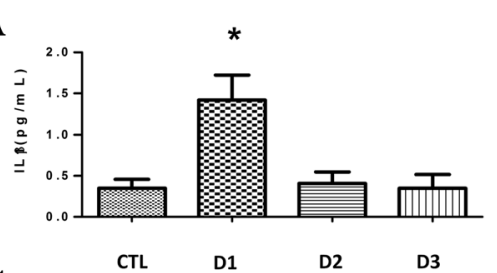

C

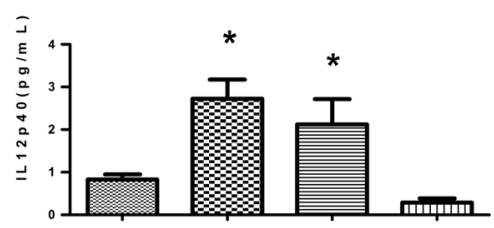

$\mathbf{E}$
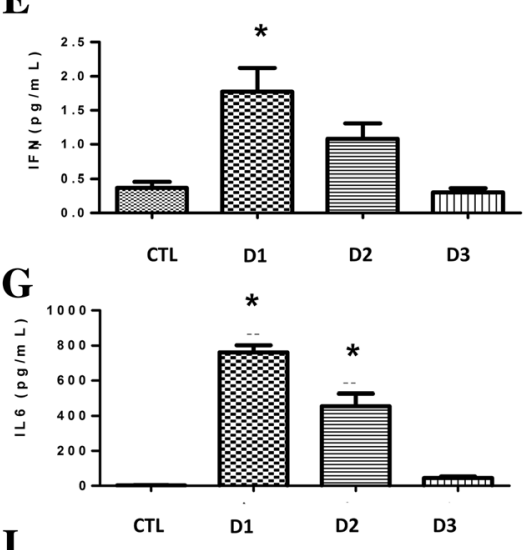

I

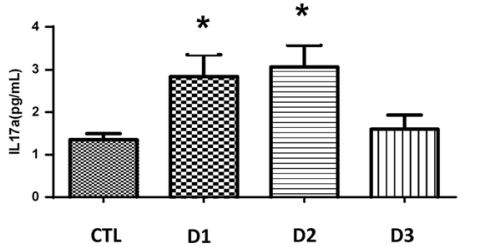

$\mathbf{K}$

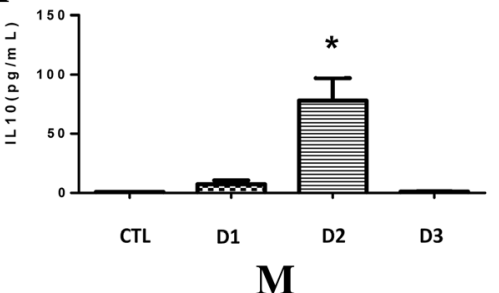

B

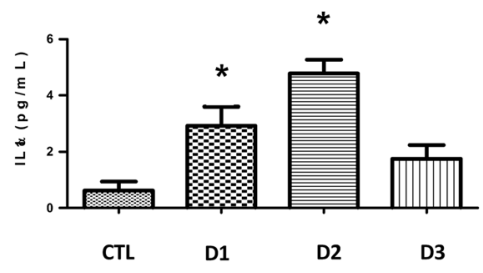

D

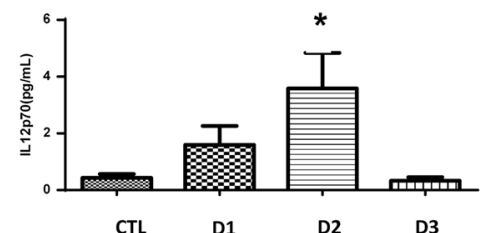

F

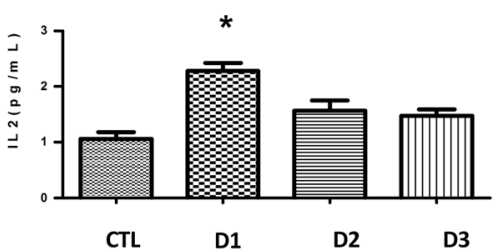

H

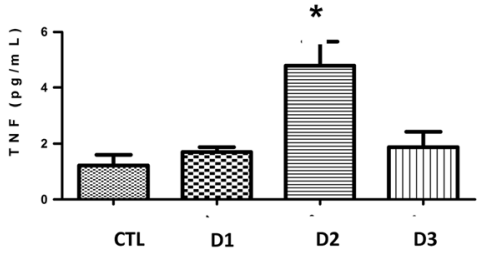

$\mathbf{J}$

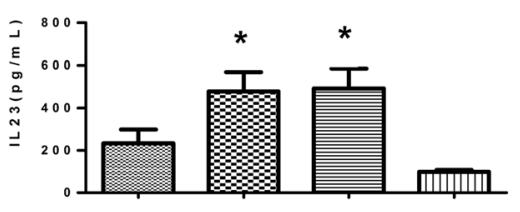

$\mathbf{L}$

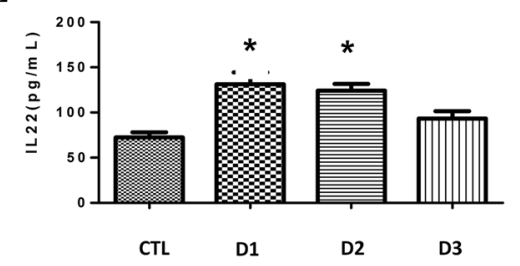

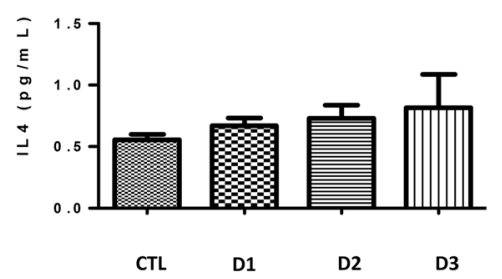

Fig. 3 Effect of HS preconditioning on the cytokines concentrations. Pro inflammatory (a-j) and Anti-inflammatory (k-m) cytokines were analyzed. Balb/c mouse serum was collected after $4 \mathrm{~h}$. Animals were allocated in 4 groups: CTL (Without treatment or insult); D1 (received one dose of $4 \mathrm{~mL} / \mathrm{kg}$ of HS 7.5\%); D2 (received one dose of $4 \mathrm{mg} / \mathrm{kg}$ of HS 7.5\% at day one and one dose of $6 \mathrm{~mL} / \mathrm{kg}$ of HS $7.5 \%$ at day three); D3 (received one dose of $4 \mathrm{~mL} / \mathrm{kg}$ of HS $7.5 \%$ at day one, one dose of $6 \mathrm{mg} / \mathrm{kg}$ of HS $7.5 \%$ at day three and one dose of $8 \mathrm{~mL} / \mathrm{kg}$ of HS $7.5 \%$ at day five). The data are represented as the mean $\pm \mathrm{SD}, n=8$ animals. ${ }^{*} p<0.05$ vs other groups, and $\# p<0.05$ vs CTL 
labeled using a GeneChip WT Terminal Labeling kit (Affymetrix, Santa Clara, CA, USA). Fragmented cDNA samples were then hybridized to GeneChip Mouse Gene 1.0 ST Arrays (Affymetrix, Santa Clara, CA, USA). Images were processed and GeneChip Command Console Software (Affymetrix) were used to generate cell intensity files (CEL files). CEL files were imported into Expression Console and normalized using robust multiarray average (RMA).

\section{Gene Chip microarray analysis}

Raw data from gene chips were summarized using RMA, which involves quantile normalization. Genes showing a statistically significance $(p<0.05)$ and a $\log 2-$ transformed fold change of at least \pm 1.5 were identified as differentially expressed. Microarray data were validated using qRT-PCR for 8 selected DEGs, which demonstrated high correlation between microarray and qRT-PCR expression levels.

\section{Statistical analysis}

All values are expressed as mean \pm standard errors of the mean (SEM). Statistical analysis was performed using InStat Statistical Software (GraphPad, La Jolla, CA, USA). Comparisons between the experimental groups were made by analysis of variance (ANOVA) or Kruskal-Wallis. A Tukey test was used as a post hoc test to compare individual groups. A log-rank test was used to analyze survival. A $p$ value less than 0.05 was considered to be significant.

\section{Results}

Three different doses of Hypertonic Saline 7,5\% (HS) $(4,6$ and $8 \mathrm{~mL} / \mathrm{kg}$ ) in alternated days were tested to determine which dose of HS was effective in inducing a preconditioning. In the HS8 group (we used increasing doses 4,6 and $8 \mathrm{~mL} / \mathrm{kg}$ to avoid hyperchloremia of animals). A lethal dose of LPS at the 8th day was injected i.p. for the survival study. We observed on Fig. 1a that hypertonic saline pre-conditioning increased animal survival after LPS injection when used increased doses of HS at the final concentration of 8 $\mathrm{mL} / \mathrm{Kg}(p<0.05)$. Figure $1 \mathrm{~b}$ shows results for negative controls comparing 7.5, 3.5 and $0.9 \% \mathrm{NaCl}$ solutions and also 20\% Manitol, the data shows effective reduction in mortality only in $7.5 \% \mathrm{NaCl}$ solution. Animals injected with PBS buffer instead LPS did not present any death.

Figure 2 shows the results of different solute for hyperosmotic solution on mortality rate after a lethal dose of LPS. The protective effect was related to sorbitol, urea and HS with the same osmotic value. Taking in account our results, we observed that preconditioning effect was osmolarity-dependent. Therefore, we looked at different solutions with the same osmolarity to find out if the preconditioning effect observed by the hypertonic saline solution would be reproducible using other solutions. We observed that all solutions were able to induce a preconditioning state and increased survival rate compared to LPS group $(p<0.05)$.

Preconditioning process was analyzed by measuring different plasmatic cytokines production. The cytokines peak presents two different patterns: Cytokines that increased their expression after first dose and then maintaining elevated expression until second dose, decreasing after third dose (Fig. 3a, c, e, f, g, i, j, l) and the cytokines that increased their expression after a second dose and decreased their expression after third dose (Fig. 3b, d, h, k).

In order to identify the possible pathway used by the hypertonic solution to induce preconditioning, we performed a micro array assay in the peritoneal macrophages of animals. Gene expression array showed an important change in several genes exposed to hypertonic solution (Table 1). For example, gene related to cytokines receptors were reduced after hypertonic solution i.e. illr2, and Mmp8. On the other hand, hypertonic solution increased Mapkbp1 and Atf3 that is related to hypertonic activation of cell signaling to preconditioning.

After confirming the potential effect of HS preconditioning in regulating the immune response, we studied whether HS preconditioning was capable to modulate systemic inflammatory response of animals subjected to endotoxemia by intraperitoneal LPS injection (Fig. 4). As expected, HS preconditioning

Table 1 Gene expression comparing hypertonic solution infusion vs. $0.9 \% \mathrm{NaCl}$ in macrophages collected from peritoneal cavity

\begin{tabular}{lll}
\hline Gene & $p$-value & Fold Change \\
\hline Lilrb4 & 0.0005 & Reduced \\
Slc7a11 & 0.0001 & -195.9 \\
II1r2 & 0.0005 & -193.9 \\
Mmp8 & 0.0001 & -190.9 \\
Scfd1 & 0.0001 & -180.5 \\
Mgam & 0.0001 & -179.9 \\
Ptgs2 & 0.0005 & -162.1 \\
& & -157.0 \\
Mapkbp1 & 0.0001 & Increased \\
Atf3 & 0.0001 & 166.9 \\
Ptprg & 0.0005 & 150.3 \\
Gm94 & 0.0005 & 150.8 \\
Ankrd & 0.0002 & 15.5 \\
Tmem126a & 0.0005 & 16.5 \\
\hline
\end{tabular}


A

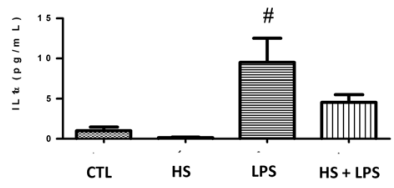

C

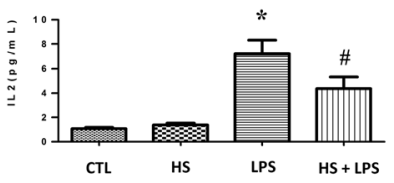

E

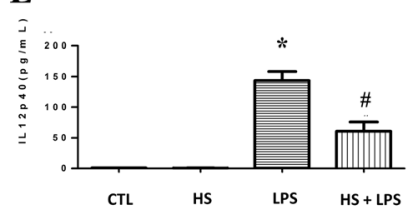

G

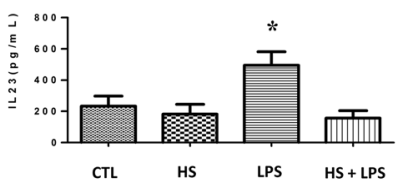

I

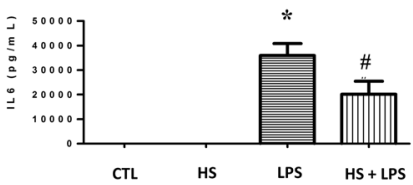

K

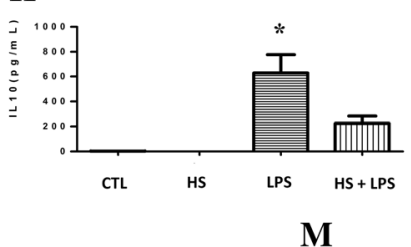

B

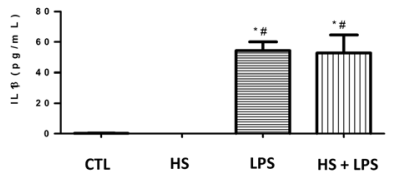

D

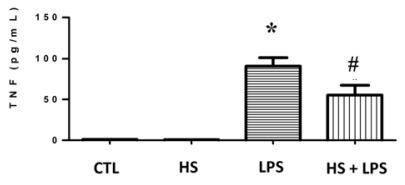

F

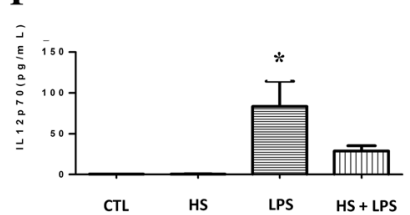

H

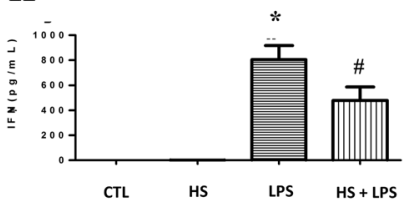

J

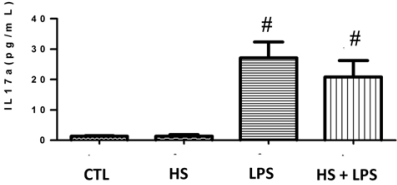

L

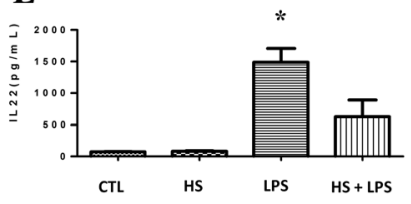

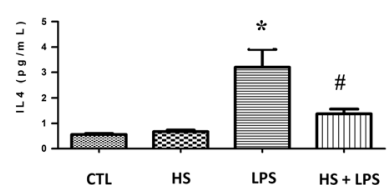

Fig. 4 Effect of HS preconditioning on the modulation of systemic inflammation after LPS injection. Pro inflammatory (a-j) and Anti-inflammatory (k-m) cytokines were analyzed. Balb/c mouse serum was collected $4 \mathrm{~h}$ after LPS injection (i.p.). Animals were allocated in 4 groups: CTL (received no injury or treatment); $\mathrm{HS}$ (received one dose of $4 \mathrm{mg} / \mathrm{kg}$ of $\mathrm{NaCl} 7.5 \%$ at day one, one dose of $6 \mathrm{mg} / \mathrm{kg}$ of $\mathrm{NaCl} 7.5 \%$ at day three and one dose of $8 \mathrm{mg} / \mathrm{kg}$ at day five); LPS (received $15 \mathrm{mg} / \mathrm{kg}$ lipopolysaccharide i.p.); HS + LPS (received $4 \mathrm{mg} / \mathrm{kg}$ at day one, $6 \mathrm{mg}$ at day 3 and $8 \mathrm{mg} / \mathrm{kg}$ at day 5 and a lethal dose of $15 \mathrm{mg} / \mathrm{kg}$ of LPS at the 8th day). The data are represented as the mean $\pm \mathrm{SD}, \mathrm{n}=8$ animals. ${ }^{*} p<0.05$ vs other groups, \# $p<0.05$ vs CTL and HS groups

decreased all cytokines production analyzed in animals treated before endotoxemia induction compared to animals without treatment $(p<0.05)$ (Fig. $4 \mathrm{a}, \mathrm{c}, \mathrm{e}, \mathrm{f}$, $\mathrm{g}, \mathrm{i}, \mathrm{j}, \mathrm{l}, \mathrm{m})$. The effect of reducing cytokines production was not related to a decrease of leucocytes or neutrophils in the blood of animals which were induced to preconditioning as shown in Fig. 5. Thus, in accordance of our hypothesis, HS preconditioning avoided systemic inflammation of endotoxemic animals. 

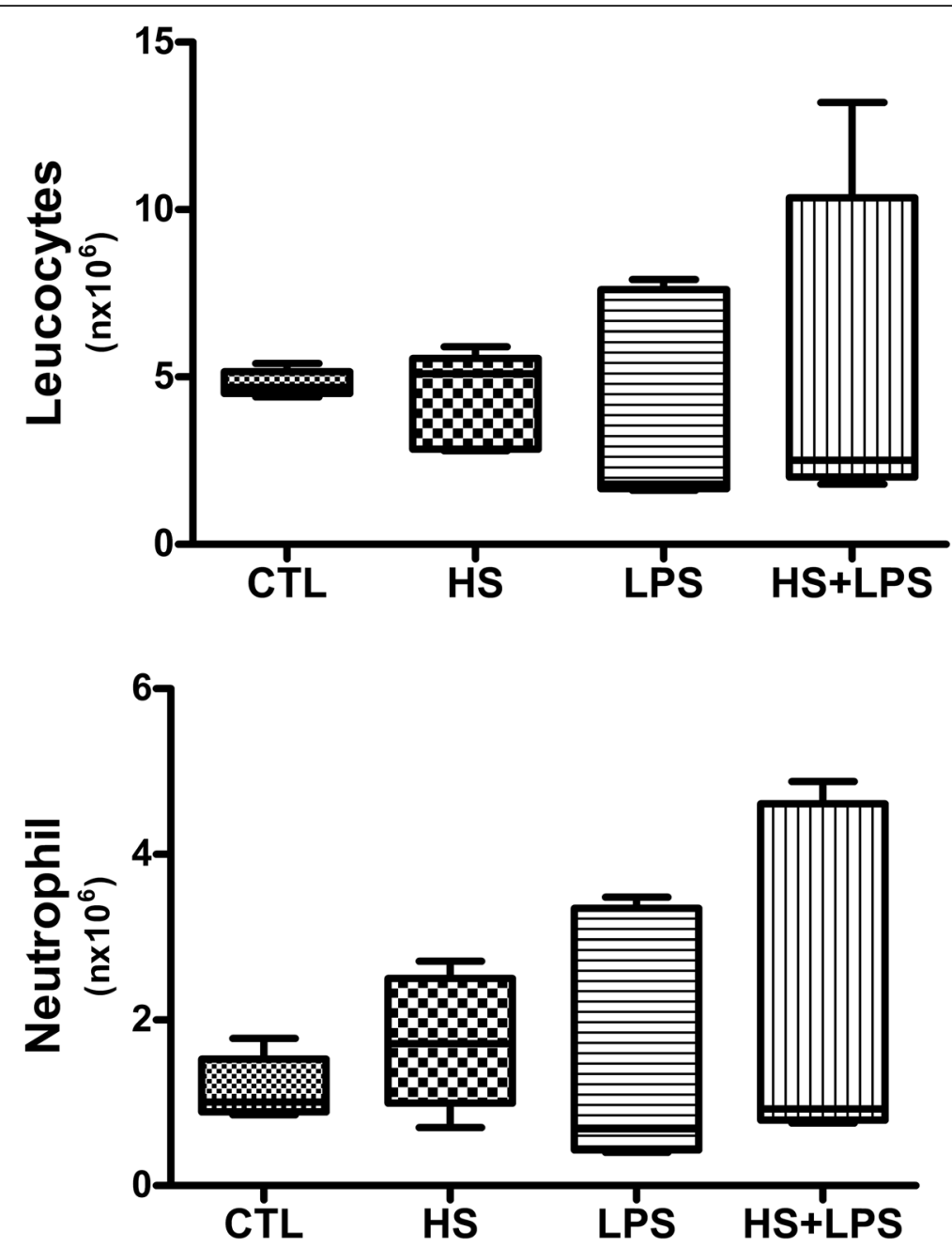

Fig. 5 Effect of HS preconditioning on the leukocytes and neutrophil after LPS injection. Leukocytes (a) and neutrophils (b) were analyzed. Balb/c mouse blood collected $4 \mathrm{~h}$ after LPS injection (i.p.). Animals were allocated in 4 groups: CTL (received no injury or treatment); HS (received one dose of $4 \mathrm{mg} / \mathrm{kg}$ of $\mathrm{NaCl} 7.5 \%$ at day one, one dose of $6 \mathrm{mg} / \mathrm{kg}$ of $\mathrm{NaCl} 7.5 \%$ at day three and one dose of $8 \mathrm{mg} / \mathrm{kg}$ at day five); LPS (received 15 mg/kg lipopolysaccharide i.p.); HS + LPS (received $4 \mathrm{mg} / \mathrm{kg}$ at day one, $6 \mathrm{mg}$ at day 3 and $8 \mathrm{mg} / \mathrm{kg}$ at day 5 and a lethal dose of $15 \mathrm{mg} / \mathrm{kg}$ of LPS at the 8 th day). The data are represented as the median $\pm \mathrm{Cl}, \mathrm{SD}, n=6$ animals

\section{Discussion}

Although the benefits of HS treatment in modulate different injuries are stablished in literature, there are no studies showing the potential of HS in vivo developing preconditioning state able to modulate inflammation. Our study provides, for the first time, data showing that repeated IV infusion of Hypertonic Solution (HS) induces a preconditioning state able to protect animals from lethal LPS injection. We showed that HS preconditioning reduced mortality rate by lethal LPS injection as well as reduced the cytokines release in plasma. Serum cytokine time course after each HS dose showed progressive preconditioning development. The mechanistic pathway related to this process involves the MAPK pathway as observed by our micro array results that showed an increasing in Mapkbp and Atf3 expression. It is noteworthy that MAPK is a kinase activated by osmotic stress and phosphorylated ATF3 which inhibit at the gene promoter the production of cytokines [25].

Experimental studies have shown some benefits of hypertonic solution compared to isotonic fluid for resuscitation after trauma and hemorrhagic shock $[8,21]$. Hypertonic solutions (HS) have been shown to reduce systemic inflammation and organ failure associated with resuscitated hemorrhagic shock [21]. Here we showed that the pretreatment with increased doses of HS $(4,6$ and $8 \mathrm{~mL} / \mathrm{Kg})$ was able to induce a preconditioning state in animals that significantly reduced mortality rate of endotoxemic animals. There is one study in vivo using the term preconditioning to HS previous to ischemia/reperfusion insult in mice [26]. However, in this study the HS was infused $1 \mathrm{~h}$ 
before ischemia/reperfusion in the animals, it is worth noting that so close infusion of HS can protect the animals not by a preconditioning effect but due to volume expansion. Other authors have verified in a similar model of ischemia/ reperfusion that HS infusion has more potent effect in different time points [27]. The authors reported that several parameters demonstrate that HS administered pre-reperfusion is more effective than administered pre-ischemia [27]. Preconditioning should present protection at any moment of infusion [21, 28].

The next question in our study was to verify whether preconditioning state was due to osmotic stress or to solute. The question is if this effect is specific to hypertonic saline or any other osmotic stress could result in similar changes [29]. Our results showed that every hyperosmolar solution were able to decrease mortality rate on endotoxemic animals, so preconditioning is dependent on hyperosmotic stress. Negative controls with lower osmotic solutions in special $0.9 \% \mathrm{NaCl}$ did not show protection as HS. Other studies on macrophage culture report that the effect of hypertonic preconditioning with either $\mathrm{NaCl}$ or mannitol is only transient, returning macrophage function within $20 \mathrm{~h}$ after hypertonic preconditioning [29]. Our results confirm that preconditioning induce by HS was effective even after an interval of $48 \mathrm{~h}$, in fact the protection last 10 days, that was the complete time of this study.

There are studies reporting that osmotic stress deflagrates intracellular signaling through mitogen-activated protein kinase (MAPK). The components of the MAPK cascades, TAK1 and MEKKs, activate IKK leading to $N F-\kappa B$ activation [30, 31]. In our analysis of gene expression comparing normal saline $(\mathrm{NaCl} 0.9 \%)$ versus hypertonic saline $(7.5 \%)$ treatment we found several genes that were changed by hypertonic solution. In particular, we highlight the finding that Mapkbp1 increased 166-fold and Atf3 increased 150-fold in animals treated with hypertonic versus saline solution. The literature showed that hormones, nutrient depletion, osmotic shock, oxidative stress, DNA damage activate Mitogenactivated/stress protein kinase (MAPK/SAPK) pathways $[25,32]$. MAPK induced the phosphorylation of transcription factors of the ATF/CREB family and regulated the transcription of target genes. Therefore, ATF3 negatively regulate transcription of pro-inflammatory cytokines. Genes that possess ATF/CREB promoter binding sites within close proximity of NF- $\mathrm{KB}$ sites, are ATF3 modulate NF- $\kappa B$ related transcription [25, 32]. Since HS induced preconditioning in animals, we hypothesized whether this preconditioning state would be able to protect animals from an acute inflammation developed by LPS injection. Our results showed that animals submitted to HS preconditioning had a decreased cytokines expression compared to animals without treatment, suggesting a therapeutically effect of HS preconditioning in controlling inflammation.

Finally, our study demonstrated for the first time that HS can induce preconditioning in vivo lasting at least 10 days. Preconditioning effect was dependent on osmotic stress, as several hyperosmotic solutions reproduces the protection to lethal LPS. HS cause alterations in inflammatory cells by modulation of different genes involved in osmotic stress (e.g. MAPK) observed by gene expression analysis. The possible mechanistic pathway is the activation of MAPK and ATF3 activation of cascade with final reduction in the production of cytokines.

\section{Conclusion}

Preconditioning effect was dependent on osmotic stress, as several hyperosmotic solutions reproduces the protection to lethal LPS. HS cause alterations in inflammatory cells by modulation of different genes involved in osmotic stress (e.g. MAPK) observed by gene expression analysis. Osmotic preconditioning was a protective effect in vivo useful in clinical practice for the pre-treatment of surgical patients submitted to risk procedures such as: reperfusion after ischemia; systemic inflammatory response or surgeries with bacterial contamination.

\section{Abbreviations}

ANOVA: Analysis of variance; ARDS: Acute respiratory distress syndrome; Atf3: Activating Transcription Factor 3 gene; CDNA: deoxyribonucleic acid copy; CREB: CAMP-response element binding protein; DEGs: Differentially expressed genes; HS: Hypertonic solution; i.p: intra peritoneal; i.v: intra venous; IFN- $\gamma$ : interferon; IKK: IKB kinase; IL (1 $\beta$, 6, 8, etc.): interleukin; IR: Ischemia reperfusion; Kg: Kilogram; LPS: Lipopolysaccharide; MAP kinases: Mitogen Activated Protein Kinases; Mapkbp1: Mitogen-Activated Protein Kinase Binding Protein 1 gene; MEKKs: Mitogen-activated protein kinase extracellular signal-regulated kinase kinase kinases; Mg: Milligram; min: minutes; MIP: Macrophage inflammatory protein; MI: Milliliter; Mmp8: metalloproteinase gene; mRNA: messenger ribonucleic acid; NFKB: nuclear factor kappa B; PBS: phosphate buffer solution; qRT-PCR: Reverse transcription polymerase chain reaction quantitative real time; RIN: RNA integrity number; SEM: Standard errors of the mean; SIRS: Systemic Inflammatory Response Syndrome; SPF: Specific pathogen-free; TAK1: Transforming growth factor beta-activated kinase; TNF-a: tumor necrosis factor a; US: United States

\section{Acknowledgements}

TO FAPESP.

\section{Authors' contributions}

RNP- performed experiments, and data analysis. MMA - performed experiments. SKA performed animal's procedures. HVB: Biochemical measurements. DFB: biochemical measurements. RCP- experiments and manuscript writing. FGS study design, data analysis, and paper writing. All authors read and approved the final manuscript.

\section{Funding}

FAPESP 15/04138-2 grant from FAPESP Fundação de Amparo a Pesquisa de São Paulo.

This work was supported by grants from: Conselho Nacional de Desenvolvimento Científico e Tecnológico (CNPq) and Fundação de Amparo à Pesquisa do Estado de São Paulo (FAPESP 2009/03338-7 and 2015/04138-2). 


\section{Availability of data and materials}

The data are available.

\section{Ethics approval and consent to participate}

Ethical criteria were met; the study was approved by the local ethical and scientific committee, and we registered with the number $248 \# / 12$.

\section{Consent for publication}

All authors have read the manuscript and agree with submission. They consent for publication.

\section{Competing interests}

The authors declare that they have no competing interests.

Received: 22 November 2018 Accepted: 18 June 2019

Published online: 03 July 2019

\section{References}

1. Angus DC, Wax RS. Epidemiology of sepsis: an update. Crit Care Med. 2001; 29:S109-16

2. Singer $M$. The new sepsis consensus definitions (Sepsis-3): the good the not-so-bad, and the actually-quite-pretty. Intensive Care Med. 2016:42:2027-9.

3. Botker HE, Lassen TR, Jespersen NR. Clinical translation of myocardial conditioning. Am J Physiol Heart Circ Physiol. 2018;314(6):H1225-52.

4. Costa FLDS, Yamaki VN, Teixeira RKC, Feijó DH, Valente AL, Carvalho LTF, Yasojima EY, Brito MVH. Perconditioning combined with postconditioning on kidney ischemia and reperfusion. Acta Cir Bras. 2017;32:599-606.

5. Gedik N, Kottenberg E, Thielmann M, Frey UH, Jakob H, Peters J, Heusch G, Kleinbongard P. Potential humoral mediators of remote ischemic preconditioning in patients undergoing surgical coronary revascularization. Sci Rep. 2017;7:12660.

6. Kohns M, Huhn R, Bauer I, Brandenburger T. Mirna-mediated mechanisms of cardiac protection in ischemic and remote ischemic preconditioning - a qualitative systematic review. Shock. 2018

7. Xie Y, Jiang D, Xiao J, Fu C, Zhang Z, Ye Z, Zhang X. Ischemic preconditioning attenuates ischemia/reperfusion-induced kidney injury by activating autophagy via the SGK1 signaling pathway. Cell Death Dis. 2018;9:338.

8. de Felippe J Jr, Timoner J, Velasco IT, Lopes OU, Rocha-e-Silva M Jr. Treatment of refractory hypovolaemic shock by $7.5 \%$ sodium chloride injections. Lancet. 1980;2:1002-4.

9. Fernandes Cl, Llimona F, Godoy LC, Negri EM, Pontieri V, Moretti Al, Fernandes TR, Soriano FG, Velasco IT, Souza HP. Treatment of hemorrhagic shock with hypertonic saline solution modulates the inflammatory response to live bacteria in lungs. Braz J Med Biol Res. 2009:42:892-901.

10. Rocha e Silva M, Velasco IT, Nogueira da Silva RI, Oliveira MA, Negraes GA, Oliveira MA. Hyperosmotic sodium salts reverse severe hemorrhagic shock: other solutes do not. Am J Phys. 1987;253(4 Pt 2):H751-62.

11. Velasco IT, Pontieri V, Rocha e Silva M Jr, Lopes OU. Hyperosmotic $\mathrm{NaCl}$ and severe hemorrhagic shock. Am J Phys. 1980;239(5):H664-73.

12. Velasco IT, Rocha e Silva M, Oliveira MA, Silva RI. Hypertonic and hyperoncotic resuscitation from severe hemorrhagic shock in dogs: a comparative study. Crit Care Med. 1989;17:261-4

13. Theobaldo MC, Barbeiro HV, Barbeiro DF, Petroni R, Soriano FG. Hypertonic saline solution reduces the inflammatory response in endotoxemic rats. Clinics. 2012:67(12):1463-8.

14. Almeida FM, Oliveira-Junior MC, Souza RA, Petroni RC, Soto SF, Soriano FG, Camillo de Carvalho PT, Albertini R, Damaceno-Rodrigues NR, Quirino Santos Lopes FDT, et al. Creatine supplementation attenuates pulmonary and systemic effects of lung ischemia and reperfusion injury. J Heart Lung Transplant. 2016:35:242-50

15. Petroni RC, Biselli PJ, Lima TM, Velasco IT, Soriano FG. Impact of time on fluid resuscitation with hypertonic saline ( $\mathrm{NaCl} 7.5 \%)$ in rats with LPSinduced acute lung injury. Shock. 2015:44:609-15.

16. Petroni RC, Cesare Biselli PJ, de Lima TM, Theobaldo MC, Caldini ET, Pimentel RN, Barbeiro HV, Kubo SA, Velasco IT, Soriano FG. Hypertonic saline $(\mathrm{NaCl} 7.5 \%)$ reduces LPS-induced acute lung injury in rats. Inflammation. 2015:38:2026-35.
17. Wade CE. Hypertonic saline resuscitation in sepsis. Crit Care. 2002;6(5):397398.

18. Gillis D, Shrode LD, Krump E, Howard CM, Rubie EA, Tibbles LA, Woodgett J, Grinstein S. Osmotic stimulation of the $\mathrm{Na}+/ \mathrm{H}+$ exchanger NHE1: relationship to the activation of three MAPK pathways. J Membr Biol. 2001;181:205-14.

19. Niswander JM, Dokas LA. Hyperosmotic stress-induced caspase-3 activation is mediated by p38 MAPK in the hippocampus. Brain Res. 2007;1186:1-11.

20. Uhlik MT, Abell AN, Johnson NL, Sun W, Cuevas BD, Lobel-Rice KE, Horne EA, Dell'Acqua ML, Johnson GL. Rac-MEKK3-MKK3 scaffolding for p38 MAPK activation during hyperosmotic shock. Nat Cell Biol. 2003:5:1104-10.

21. Rhind SG, Crnko NT, Baker AJ, Morrison LJ, Shek PN, Scarpelini S, Rizoli SB. Prehospital resuscitation with hypertonic saline-dextran modulates inflammatory, coagulation and endothelial activation marker profiles in severe traumatic brain injured patients. J Neuroinflammation. 2010:7:5.

22. Medzhitov R, Janeway CA, Jr:: An ancient system of host defense. Curr Opin Immunol 1998, 10:12-15.

23. Melo ES, Goloubkova T, Barbeiro DF, Gorjão R, Vasconcelos D, Szabo C, Curi R, de Lima Salgado TM, Velasco IT, Soriano FG. Endotoxin tolerance: selective alterations in gene expression and protection against lymphocyte death. Immunobiology. 2010;215:435-42.

24. Melo ES, Barbeiro DF, Gorjao R, Rios ECS, Vasconcelos D, Velasco IT, Szabo C, Curi R, de Lima-Salgado TM, Soriano FG. Gene expression reprogramming protects macrophage from septic-induced cell death. Mol Immunol. 2010;47:2587-93.

25. Gao J, Wagnon JL, Protacio RM, Glazko GV, Beggs M, Raj V, Davidson MK, Wahls WP. A stress-activated, p38 mitogen-activated protein kinase-ATF/ CREB pathway regulates posttranscriptional, sequence-dependent decay of target RNAs. Mol Cell Biol. 2013;33:3026-35.

26. Oreopoulos GD, Wu H, Szaszi K, Fan J, Marshall JC, Khadaroo RG, He R, Kapus A, Rotstein OD. Hypertonic preconditioning prevents hepatocellular injury following ischemia/reperfusion in mice: a role for interleukin 10. Hepatology. 2004:40:211-20.

27. Figueira ER, Bacchella T, Coelho AM, Sampietre SN, Molan NA, Leitao RM, Machado MC. Timing-dependent protection of hypertonic saline solution administration in experimental liver ischemia/reperfusion injury. Surgery. 147:415-23.

28. Rizoli SB, Kapus A, Parodo J, Rotstein OD. Hypertonicity prevents lipopolysaccharide-stimulated CD11b/CD18 expression in human neutrophils in vitro: role for p38 inhibition. J Trauma. 1999;46:794-8 discussion 798-799.

29. Cuschieri J, Gourlay D, Garcia I, Jelacic S, Maier RV. Hypertonic preconditioning inhibits macrophage responsiveness to endotoxin. J Immunol. 2002;168:1389-96.

30. Huangfu WC, Omori E, Akira S, Matsumoto K, Ninomiya-Tsuji J. Osmotic stress activates the TAK1-JNK pathway while blocking TAK1-mediated NFkappaB activation: TAO2 regulates TAK1 pathways. J Biol Chem. 2006:281:28802-10.

31. Schlesinger TK, Fanger GR, Yujiri T, Johnson GL. The TAO of MEKK. Front Biosci. 1998:3:D1181-6.

32. Thompson MR, Xu D, Williams BR. ATF3 transcription factor and its emerging roles in immunity and cancer. J Mol Med (Berl). 2009;87:1053-60.

\section{Publisher's Note}

Springer Nature remains neutral with regard to jurisdictional claims in published maps and institutional affiliations.

Ready to submit your research? Choose BMC and benefit from:

- fast, convenient online submission

- thorough peer review by experienced researchers in your field

- rapid publication on acceptance

- support for research data, including large and complex data types

- gold Open Access which fosters wider collaboration and increased citations

- maximum visibility for your research: over $100 \mathrm{M}$ website views per year

At $\mathrm{BMC}$, research is always in progress.

Learn more biomedcentral.com/submissions 